American Journal of Environmental Sciences 6 (5): 449-454, 2010

ISSN 1553-345X

(C) 2010 Science Publications

\title{
Solar Radiation at Total Solar Eclipse, 29-March 2006, at Tobruq
}

\author{
${ }^{1}$ A.H. Hassan and ${ }^{2}$ U. Ali Rahoma \\ ${ }^{1}$ Department of Physics, Faculty of Education, \\ Omer El- Mukhtar University, Tobruk, Libya \\ ${ }^{2}$ Department of Radiology, Faculty of Medical Technology, \\ Omer El- Mukhtar University, Tobruk, Libya
}

\begin{abstract}
Problem statement: Measurement of the different components of solar radiation and fractions of these components for the global (horizontal and tracker), direct (white and three colors, yellow, red and infrared) and diffuse solar radiation during the solar eclipse, 29 March 2006 at Tobruq, Libya (Lat. $32.08^{\circ} \mathrm{N}$ and Long. $23.98^{\circ} \mathrm{E}$ ). The time interval of solar eclipse was $2 \mathrm{~h}: 40 \mathrm{~m}$ and the maximum magnitude of eclipse at this region was 0.995 . Conclusion: The results showed that the maximum percent of color in the total direct solar radiation during the true eclipse from the first contact to the end contact was in the infrared, where the percent were in the green $(11.74 \%)$, yellow $(15.69 \%)$, red (14.88\%) and infrared (57.68\%).
\end{abstract}

Key words: Solar radiation components, Relative Humidity $(\mathrm{RH})$, total solar eclipse, metrological data, color portion, Potsdam filters, global horizontal, Global Tracker (GT), diffuse, atmospheric, synchronous, Temperature Dray (Td)

\section{INTRODUCTION}

On Wednesday, 2006 March 29, a total eclipse of the Sun was visible from within a narrow corridor which traversed half the Earth. The path of the Moon's umbra shadow began in Brazil and extended across the Atlantic, northern Africa and central Asia, where it ended at sunset in northern Mongolia. A partial of eclipse was seen within the much broader path of the moon's penumbral shadow, which included the northern two thirds of Africa, Europe and central Asia.

The instant of greatest eclipse occurred at 10:11:18 UT when the axis of the moon's shadow passed closest to the center of Earth. Totality reached its maximum duration of $4 \min 7 \mathrm{sec}$, the Sun's altitude was $67^{\circ}$, the path width was $184 \mathrm{~km}$ and the umbra's velocity was $0.697 \mathrm{~km} \mathrm{sec}^{-1}$. Continuing on a northeastern course, the umbra crossed central Libya and reached the Mediterranean coast at 10:40 UT. Northwestern Egypt also lied within the umbral path, where the central duration was 3 min $58 \mathrm{sec}$ (Espenak and Anderson, 2004; Chaouachi and Gabsi, 2007).

Many researches around this subject were carried out in the world especially in this region. (Copaciu and Yousef, 1999; Hazami et al., 2005), In Romania, a study of atmospheric responses due to the 11 August total solar eclipse indicated that both of the global and UVB radiation dropped dramatically to a minimum around totality. There was a chance to study attenuation of such a radiation due to clouds. The net radiation became negative for about $17 \mathrm{~min}$ at Caldarusani. The temperature dropped to about $30^{\circ} \mathrm{C}$ following totality at both Afumati and Clarasi, although at the beginning of eclipse it was about $46.5^{\circ} \mathrm{C}$ at Afumati and $34^{\circ} \mathrm{C}$ at Cãalãarasi. At Caldarusani, the surface temperature dropped from $34.1-29^{\circ} \mathrm{C}$. It seemed that the air temperature inside the umbra was between $29-30^{\circ} \mathrm{C}$. The response time of minimum surface temperature was about $18 \mathrm{~min}$, which was comparable to the duration of the negative part of the net radiation when the backward radiation became higher than the incident radiation (Copaciu and Yousef, 1999). Rahoma et al., 1999; 2007; Alam et al., 2005) studying the spectral composition of global solar radiation by the interference metallic filter during the eclipse of 1999 August 11 (as the partial solar eclipse, $70 \%$ covering of solar disk in Helwan, Egypt). The conclude indicated that, there was an increase in the hole with different zonal summer times in the interval 350-450 nm but without risks on the human eye; that interval lied in the end of the ultraviolet solar radiation. Minimum lied between 500-700 $\mathrm{nm}$. This interval represented the normal maximum peak of the solar spectrum and go from 700nm up to $900 \mathrm{~nm}$ which related to the infrared interval and down in the deep infrared from $900 \mathrm{~nm}$ to the end. The ultraviolet band was suffering low depression with respect to other bands but was not given any risks on the human life as common.

Corresponding Author: A.H. Hassan, Department of Physics, Faculty of Education, Omer El- Mukhtar University, Tobruk, Libya Tel: +218-92-6260520 
That the change in meteorological parameter related to variability in the solar spectrum that shifted the short wave before $600 \mathrm{~nm}$ to long wave around $1000 \mathrm{~nm}$. The maximum drop in the solar spectrum lied in the interval which consisted of the normal peak of the solar spectrum from 500-600 nm (Rahoma et al., 1999). Hassan et al. (2004), studying the depression of different solar radiation components during the solar eclipse, 11 August 1999 over Egypt (as the partial solar eclipse, $70 \%$ covering of solar disk in Helwan, Egypt). The maximum depression values in different components of solar radiation was $54 \%$ in red solar radiation (for all global and direct), while the minimum depression was in infra red solar radiation (34\% for global and $41 \%$ for direct). The clearness index and the diffuse fraction were 0.634 and 0.232 respectively. The atmospheric red is $7.4 \%$ and the atmospheric infra red was $10.7 \%$, the percentage of ultra violet was 3\% (Hassan et al., 1999).

The aim of the present study was to determine the color portion for different components of the solar radiation during the solar eclipse occurred on 29 March 2006 at Tobruq, Libya.

\section{Nomenclature:}

$\mathrm{G}_{0}$ : $\quad$ Extra terrestrial global solar radiation, 250-25 $000 \mathrm{~nm}$.

GT: Measurements of tracker global solar radiation, 290-2 $800 \mathrm{~nm}$.

G: Measurements of horizontal global solar radiation, 290-2 $800 \mathrm{~nm}$.

I: Measurements of direct total solar radiation, 290-2 $800 \mathrm{~nm}$.

Y: Measurements of direct yellow solar radiation, 530-2 $800 \mathrm{~nm}$.

YC: $\quad$ Measurements of direct yellow color, 530- 630 nm.

R: Measurements of direct red solar radiation, 630-2 $800 \mathrm{~nm}$.

RC: $\quad$ Measurements of direct red color, 630-695 nm.

IR: Measurements of direct infra red solar radiation, 695-2 $800 \mathrm{~nm}$.

$\mathrm{K}_{\mathrm{d}}$ : $\quad$ Diffuse fraction, $\mathrm{D} / \mathrm{G}$.

L. M.T: Local Mean Time (hour).

Td: $\quad$ Air temperature.

R.H: Relative humidity.

a: $\quad$ Altitude of the sun.

Az: Azimuth of the sun, measured from the north direction. direction.

Instruments and measurements: The observation of eclipse taken in Libya, Tubruq, $32^{\circ} 05^{\prime} \mathrm{N} 023^{\circ} 59^{\prime} \mathrm{E}$, near the Mediterranean coast on the roof top of a building, $30 \mathrm{~m}$ elevation on the sea level and the background was considered to be a desert, the weather was clear and cloudless.

The Georgi type Actinometer instrument was used for measurements of the solar radiation components. The massiveness of the tube body minimized the effect of the ambient temperature fluctuations. In the head of the tube besides the shutter there were three metal sheets and turn able filter discs which had four openings. Usually one being empty was used to complete spectrum bands (non classical individual bands WG7 and GG22). Other opening had Potsdam filters OG1, 2 and RG8 (WG7 (WG295) the range was from 290-2900, OG1 (OG (530), the range was from 530-2900, RG2 (RG630) the range from 630-2900, RG8 (RG695) the range was from 695-2900), all of these filters were $3 \mathrm{~mm}$ width. The radiation meter that was coupled with this instrument was a voltmeter (Mosalam Shaltout et al., 1995; 2000a; Tadros et al., 2002; Jahanshah et al., 2009). The parameters that were under the study were; global horizontal (G), Global Tracker (GT), diffuse as D = GT-I, total direct (I), different components of direct as yellow ( $\mathrm{Y}=530-2900$ $\mathrm{nm})$, red $(\mathrm{R}=630-2900 \mathrm{~nm})$ and infra red $(\mathrm{IR}=695-$ $2900 \mathrm{~nm})$. Besides to the color band (C) as the green color $=\mathrm{I}-\mathrm{Y}$, Yellow Color $(\mathrm{YC})=\mathrm{Y}-\mathrm{R}$, Red Color $(\mathrm{RC})$ $=\mathrm{R}-\mathrm{IR}$. The air Temperature Dray (Td), the Relative Humidity (RH) (Mosalam Shaltout et al., 1993; 2000b).

\section{RESULTS}

Table 1 represented the time of the first contact, maximum and last contact of eclipse as the local mean time beside the eclipse magnitude, eclipse observation, altitude (a), azimuth (Az) of the sun at this duration (Espenak and Anderson, 2004). Also the values of the metrological conditions as the air temperature $\left(\mathrm{Td}, \mathrm{C}^{\mathrm{o}}\right)$ and Relative Humidity (R.H, \%) during the phasing of the solar eclipse are measured. As seen from this table, the interval of eclipse (from the first contact to the last contact) at this location was $2 \mathrm{~h}: 39 \mathrm{~m}: 22.8 \mathrm{sec}$, the depression of global and direct components executed to depression for the temperature at the maximum eclipse $\left(1.5 \mathrm{C}^{\circ}\right)$ from the first contact and hence increased to $3 \mathrm{C}^{\circ}$ at the end contact, at the same time the R.H increasing $20 \%$ and hence decreasing to $4 \%$.

Figure 1 shows the hourly variation of the Global horizontal (G), Global Tracker (GT) and Diffuse (D) solar radiation during the total day (from the sunrise to sunset) including the depression of the radiation solar components at the interval of solar eclipse. Figure 2 Shows the hourly variation of ratio for the $(\mathrm{GT} / \mathrm{G})$ and $(\mathrm{GT} / \mathrm{I})$ on the day, which give the high ratio $\mathrm{GT} / \mathrm{G}$ in the morning and the evening, where the diffuse at this time is large because the air mass is large. 
Am. J. Environ. Sci., 6 (5): 449-454, 2010

Table1: State of the sun and metrological conditions during the eclipse

\begin{tabular}{lllllll}
\hline $\begin{array}{l}\text { Duration of } \\
\text { eclipse }\end{array}$ & $\begin{array}{l}\text { Time } \\
\text { hh:mm:ss }\end{array}$ & $\begin{array}{l}\text { Eclipse } \\
\text { magnitude }\end{array}$ & $\begin{array}{l}\text { Eclipse } \\
\text { Observation }\end{array}$ & A degree & Az degree & Td ${ }^{\circ} \mathrm{C}$ \\
\hline First contact & $11: 19: 26$ & 0.000 & 0.000 & 56.8 & 146 & 19.5 \\
Maximum eclipse & $39: 02.7$ & 0.995 & 0.998 & 61.3 & 184 & 62 \\
Last contact & $58: 48.8$ & 0.000 & 0.000 & 54.8 & 220 & 8.0 \\
\hline
\end{tabular}

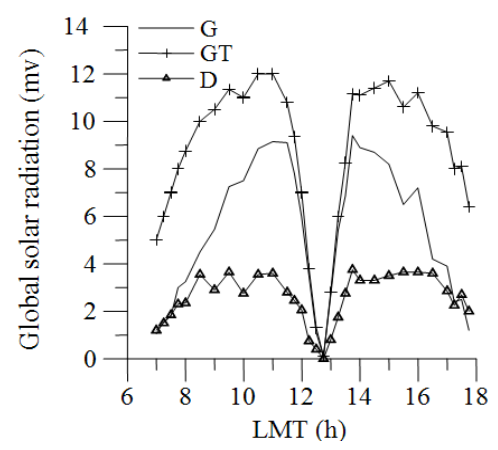

Fig. 1: The hourly variation of G, GT and D

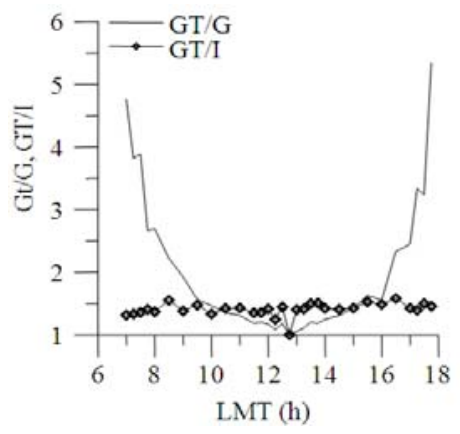

Fig. 2: The hourly variation of GT/GI

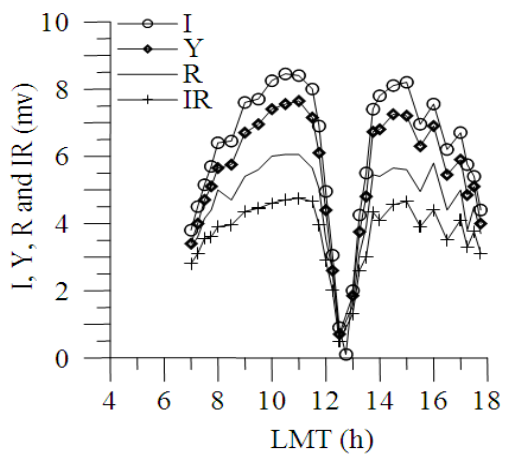

Fig. 3: The hourly variation of I, Y, R and RI

Figure 3 Shows the hourly variation of the direct components, total direct (I), yellow (Y), Red (R) and Infra Red (IR) during the total day including the depression of the radiation solar components at the interval of solar eclipse.

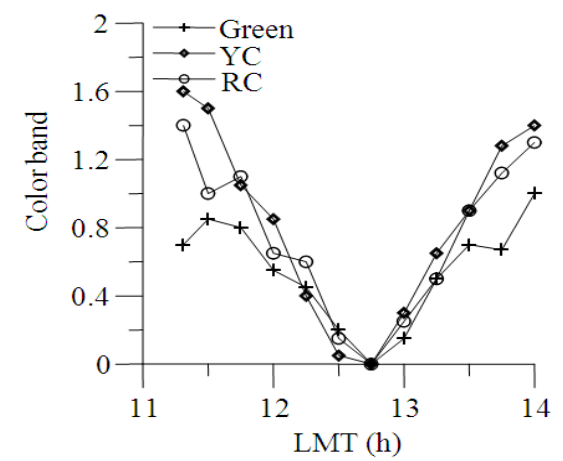

Fig. 4: The hourly variation of Green, YC and RC

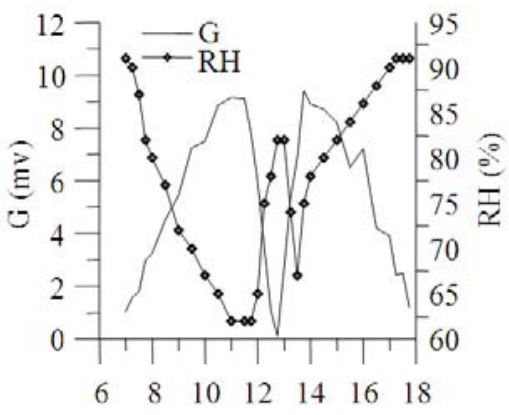

Fig. 5: The hourly variation of $\mathrm{G}$ and $\mathrm{RH}$

Figure 4 Show the hourly variation of the color band, green, $\mathrm{YC}$ and $\mathrm{RC}$ during the true eclipse (true-E) from the first contact to the last contact. Figure 5 Shows the hourly variation of global solar radiation $(G)$ and Relative Humidity (RH) during the total day, where the relation is inversely as seen at the maximum eclipse. Figure 6 Shows the hourly variation of the Global solar radiation $(\mathrm{G})$ and the air Dry Temperature (Td) during the eclipse, where the relation is proportionally as seeing at the maximum eclipse. Figure 5 and 6shows that, the depression of air temperature (Td) is synchronous to the depression of Global solar radiation $(\mathrm{G})$, while the Relative Humidity (RH) is increased during the solar eclipse and especially at the maximum of eclipse. The decrease in temperature and increase in relative humidity developments during the eclipse are showing in Table 1. Figure 7 Shows the hourly variation of air temperature (Td) and Relative Humidity (RH) during the interval of observation, where the relation is inversely. 
Am. J. Environ. Sci., 6 (5): 449-454, 2010

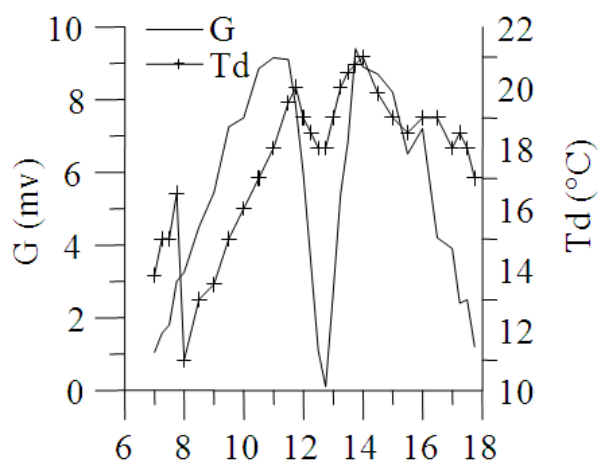

Fig. 6: The hourly variation of $\mathrm{G}$ and $\mathrm{Td}$

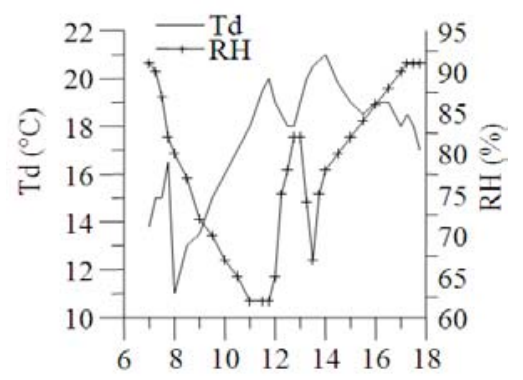

Fig. 7: The hourly variation of Td and RH

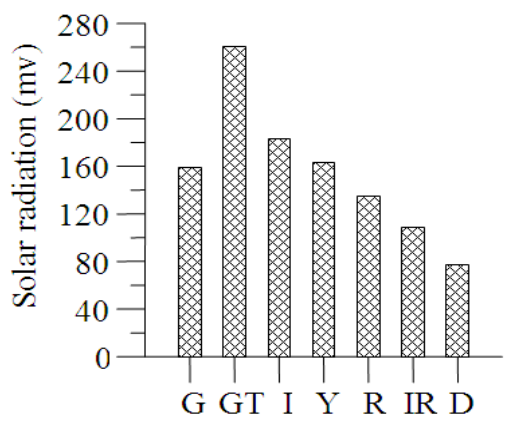

Fig. 8: Daily values of solar radiation

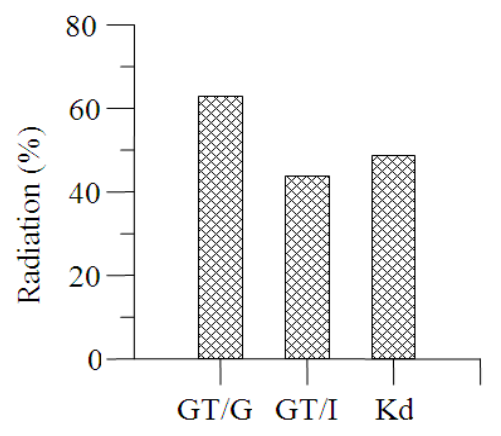

Fig. 9: Daily values of GT/G, GT/I and Kd

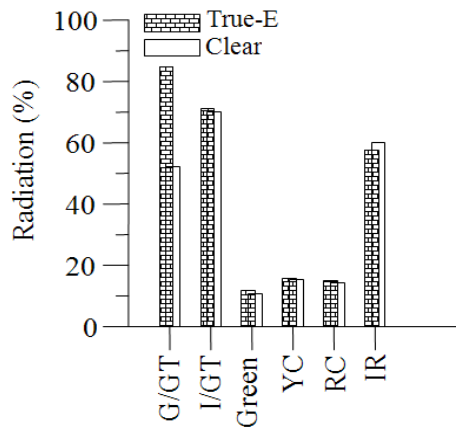

Fig. 10: The percent of color during the eclipse (E) and clear

Figure 8 Shows the comparison for the different values of the solar radiation components, GT, G, I, Y, R, IR and $\mathrm{D}$ during the interval of observation (total day). Figure 9 Show the ratio of solar radiation (GT/G), (GT /I) and the diffuse fraction $(\mathrm{Kd}=\mathrm{D} / \mathrm{G})$. Figure 10 Gives the percent of $(\mathrm{G} / \mathrm{GT}),(\mathrm{I} / \mathrm{GT})$, Green, YC, RC and IR color values of solar radiation during the true solar eclipse (true-E) and clear interval as the comparison. Table 2 represents the values of the solar radiations GT, G, I, Y, R, IR and D = GT-I, beside to the diffuse fraction $\mathrm{Kd}=\mathrm{D} / \mathrm{G}$ for three cases, the first case represent the total values (during the total interval of observation, from sunrise to sunset). The second case represents the true eclipse (True-E) from the first contact to the last contact, ( $2 \mathrm{~h}: 39 \mathrm{~m}: 22.8 \mathrm{sec})$. The third case represent the clear observation (the total observation subtract true eclipse), which mean the interval of observation without eclipse. From this table it is clear that, the GT (260) $>\mathrm{G}(158.92)>\mathrm{D}(77.5)$, where the GT including the direct (I) and the Diffuse (D) solar radiation. Also the value of $(\mathrm{I}=182.5)>(\mathrm{Y}=$ $162.5)>(\mathrm{R}=134.55)>(\mathrm{IR}=108.33)$ and all the bands are depressions during the interval of eclipse. In addition, this curve give the green color band $($ Green $=$ $\mathrm{I}-\mathrm{Y}=20$ ), yellow color band $(\mathrm{YC}=\mathrm{Y}-\mathrm{R}=27.95)$, Red Color band $(\mathrm{RC}=\mathrm{R}-\mathrm{IR}=26.22)$, infra red color band $(\mathrm{IR}=108.33)$. This means that the percent of color during the observation time with respect to the direct are in the green is $(10.96 \%)$, yellow is $(15.32 \%)$, red is $(14.36 \%)$ and IR is $(59.35 \%)$. These results shown that, the color prevalent during the observation time is infra red then yellow then red and then green. Table 3 represent the measurements and calculated values for three cases (Total, True-E and Clear) of the percentage of the Global horizontal solar radiations $(\mathrm{G})$, with respects to GT (G/GT), direct solar radiation (I) to $G_{T}$ (I/GT), diffuse solar radiation (D) to the GT, green color (I-Y) to the direct (I), Yellow Color (Y-R) to the I, Red Color (R-IR) to the I and Infra Red color (IR) to the I. 452 
Am. J. Environ. Sci., 6 (5): 449-454, 2010

Table 2: Represents the values of the solar radiations GT, G, I, Y, R, IR and D = GT-I, beside to the diffuse fraction Kd $=\mathrm{D} / \mathrm{G}$ for three cases, the first case represent the total values (during the total interval of observation). The second case represents the true eclipse (True-E) from the first contact to the end contact. The third case represent the clear observation (the total observation subtract true eclipse)

\begin{tabular}{|c|c|c|c|c|c|c|c|c|}
\hline Case & G & GT & I & Y & $\mathrm{R}$ & IR & $\mathrm{D}$ & $\mathrm{Kd}$ \\
\hline Total & 158.92 & 260.00 & 182.50 & 162.68 & 134.55 & 108.33 & 77.5 & 48.76 \\
\hline True. E & 60.75 & 71.65 & 50.85 & 44.88 & 36.90 & 29.33 & 20.8 & 30.84 \\
\hline Clear & 98.17 & 188.35 & 131.65 & 117.80 & 97.65 & 79.00 & 56.7 & 17.92 \\
\hline
\end{tabular}

Table 3: Measurements and calculated values for three cases (Total, True-E and Clear) of the percentage of (G/GT), (I/GT), (D/ GT), (I-Y)/I, $\mathrm{YC} / \mathrm{I}, \mathrm{RC} / \mathrm{I}$ and IR/I

\begin{tabular}{|c|c|c|c|c|c|c|}
\hline Case & $(\mathrm{G} / \mathrm{GT})(\%)$ & I/GT (\%) & $\begin{array}{l}\text { Green \% } \\
(\mathrm{I}-\mathrm{Y} / \mathrm{I})\end{array}$ & $\begin{array}{l}(\mathrm{YC} / \mathrm{I}) \% \\
(\mathrm{Y}-\mathrm{R} / \mathrm{I})\end{array}$ & $\begin{array}{l}(\mathrm{RC} / \mathrm{I}) \% \\
(\mathrm{R}-\mathrm{IR} / \mathrm{I})\end{array}$ & $\begin{array}{l}\text { IR \% } \\
(\mathrm{IR} / \mathrm{I})\end{array}$ \\
\hline Total day & 61.12 & 70.19 & 10.86 & 15.41 & 14.37 & 59.36 \\
\hline True. E & 84.79 & 70.97 & 11.74 & 15.69 & 14.88 & 57.68 \\
\hline Clear & 52.12 & 69.89 & 10.52 & 15.30 & 14.17 & 60.00 \\
\hline
\end{tabular}

Dissections and comments on Table 2 and 3: In Table 2 around the values of $\mathrm{G}$ and GT comparison with $\mathrm{I}$ in case true-E, it is found that the GT (71.65) $>\mathrm{G}$ (60.75) $>$ I (50.85). This meant that it was favorable for the GT mode in case the total eclipse or semi total eclipse hence the $\mathrm{G}$ mode, while the I mode was weak. Table 3 shows the percent of horizontal global solar radiation $(\mathrm{G})$ was large $(84.8 \%)$ with respect to the total $(61.12 \%)$ and clear $(52.12 \%)$, where the prevalent of radiation in this case was diffused from the all sky especially in absent or weak direct radiation. It was noticed that the, I/ GT \% were almost the same values in the three cases $(70.19,70.97$ and $69.89 \%)$, whereas in case of the colors, the percentage were large in true-E comparable with the clear case in three colors were (green 11.74>10.52\%), (yellow 15.69>15.3\%) and (red $14.88>14.17 \%)$. In case of infrared the clear was larger than the true-E $(60>57.68 \%)$.

Also in Table 2 around $\mathrm{D}$ and $\mathrm{Kd}=\mathrm{D} / \mathrm{G}$, it was noticed that the percent of $\mathrm{Kd}$ in case true-E was larger than the percent of $\mathrm{Kd}$ in clear $(30.84>17.92 \%)$. Where part of direct radiation outer atmosphere was juvenile of diffraction and scattered radiation when the rays crashed on the edge of the moon. Thus the source of radiation at the eclipse outer atmosphere were because of the direct radiation from the sun and the rays that diffracted from the edge of the moon, which passed throw the contents of atmospheric layers, where there were multi collisions and hence it increased the diffuse solar radiation. The percent of diffuse radiation in case of the eclipse was larger than the percent of the total global radiation which came from the part sector from the sky.

\section{CONCLUSION}

The results showed that, during the true solar eclipse from the first contact to the last contact were:
- The maximum percent of color in the total direct solar radiation was in the infrared, where the percent were green $(11.74 \%)$, yellow $(15.69 \%)$, red (14.88\%) and infrared (57.68\%)

- The diffuse fraction was $30 \%$ from the tracker global solar radiation

- The depression of the air temperature was synchronous to the depression of solar radiation components, while the relative humidity increased during the solar eclipse and especially at the eclipse maximum.

\section{REFERENCES}

Alam, M.S., S.K. Saha, M.A.K. Chowdhury, M. Saifuzzaman, M. Rahman, 2005. Simulation of solar radiation system. Am. J. Applied Sci., 2: 751-758. DOI: $10.3844 / .2005 .751 .758$

Chaouachi, B. and S. Gabsi, 2007. Design and simulation of an absorption diffusion solar refrigeration unit. Am. J. Applied Sci., 4: 85-88. DOI: $10.3844 / .2007 .85 .88$

Copaciu, V. and S.M. Yousef, 1999. Some atmospheric responses the 11 August 1999 total solar eclipse near Bucharest. Rom. Astron. J., 9: 19-23. http://adsabs.harvard.edu/abs/1999RoAJ...9S..19C

Espenak, F. and J. Anderson, 2004. Total Solar Eclipse of 2006 March 29. NASA/TP-2004-212762

Jahanshah, F., K. Sopian, S.H. Zaidi, M.Y. Othman and N. Amin et al., 2009. Modeling the effect of P-N junction depth on the output of planer and rectangular textured solar cells. Am. J. Applied Sci., 6: 667-671. DOI: 10.3844/.2009.667.671

Hassan, A.H., M.A. Shaltout and U.A. Rahoma, 1999. The depression of different solar radiation components during the solar eclipse, 11 August 1999 over Egypt. J. Astron. Soc. Egypt, 12: 70-81. 
Hazami, M., S. Kooli, M. Lazaar, A. Farhat and A. Belghith, 2005. Thermal performance of a solar heat storage accumulator used for greenhouses conditioning. Am. J. Environ. Sci., 1: 270-277. DOI: $10.3844 / .2005 .270 .277$

Mosalam Shaltout, M.A., M. Tadros and M. ElMetwally, 1993. Solar spectrum and air pollution in Cairo. Proceeding of the ISES Solar World Congress, August 1993, Budapest, Hungary, pp: 217-222.

Mosalam Shaltout, M.A., M. Tadros and M. ElMetwally, 1995. Relative reduction of direct solar radiation by aerosols in Cairo centre. Proceeding for the Energy Efficiency and Environmental, Protection Conference and Exhibition, Mar. 26-30, Cairo, Session ENV-5, pp: 20-26.

Mosalam Shaltout, M.A., M. Tadros and M. ElMetwally, 2000a. Atmospheric turbidity parameters affecting the incident radiation for two different areas in Egypt. Arab J. Nuclear Sci. Appl., 33: 177-191.
Mosalam Shaltout, M.A., M.T.Y. Tadros and M. ElMetwally, 2000b. Studying the extinction coefficient due to aerosol particles at different spectral bands in some regions at Cairo. J. Renew. Energy, 19: 597-615. DOI: 10.1016/S09601481(99)00077-4

Rahoma, U. Ali., M.A. Shaltout and A.H. Hassan, 1999. Study of spectral global solar radiation during the partial solar eclipse of 11 August 1999 at Helwan, Egypt. J. Astron. Soc. Egypt, 12: 31-45.

Rahoma, Ali U. and A.H. Hassan, 2007. Fourier transforms investigation of global solar radiation at true noon: In the desert climatology. Am. J. Applied Sci., 4: 902-907. DOI: 10.3844/.2007.902.907

Tadros, M.T.Y., M. El-Metwally and A.B. Hamed, 2002. Determination of Ångström coefficients from spectral aerosol optical depth at two sites in Egypt. Renew. Energy, 27: 621-45. DOI: 10.1016/S0960-1481(01)00156-2 